\title{
Benefício de Prestação Continuada e perícia médica previdenciária: limitações do processo*
}

\section{Continued benefit and social security medical evaluation: limitations of the process}

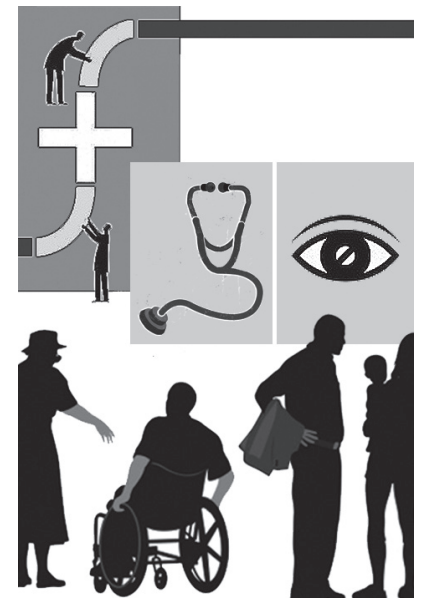

\author{
Miriam Cláudia Spada Bim** \\ Neide Tiemi Murofuse***
}

\begin{abstract}
Resumo: Com o objetivo de analisar os resultados do processo de avaliação da pessoa com deficiência $(\mathrm{PcD})$ requerente do Benefício de Prestação Continuada (BPC) — após a implantação do modelo de avaliação baseado na Classificação Internacional de Funcionalidade, Incapacidade e Saúde (CIF) - foi desenvolvido um estudo documental envolvendo a análise estatística descritiva de 1.404 requerimentos de BPC para PcD, no período de maio de 2006 a abril de 2012. Os resultados evidenciaram a permanência da estrutura de exclusão, com a avaliação adotada, mantendo-se a restritividade de acesso da $\mathrm{PcD}$ ao BPC.

Palavras-chave: Perícia médica Previdenciária. Avaliação social da deficiência. Proteção social.
\end{abstract}

\begin{abstract}
Aimed at analyzing the results of the process of evaluation of the disabled people who ask for the Continued Benefit - after the implementation of the model of evaluation based on the
\end{abstract}

* Artigo extraído da dissertação "Benefício de Prestação Continuada: uma análise da avaliação da pessoa com deficiência antes e depois de instituído o modelo baseado na CIF", apresentada ao Programa de Mestrado em Biociências e Saúde, da Universidade Estadual do Oeste do Paraná (Unioeste), câmpus de Cascavel.

** Assistente Social, Analista do Seguro Social do Instituto Nacional do Seguro Social (INSS), mestranda do Programa de Pós-Graduação em Biociências e Saúde da Unioeste, Toledo/PR, Brasil. E-mail: mirian_bim@hotmail.com.

*** Doutora em Enfermagem Fundamental, professora aposentada da Unioeste, câmpus de Cascavel/ PR, Brasil; docente do Programa de Mestrado em Biociências e Saúde da Unioeste, câmpus de Cascavel. E-mail: neidetm@terra.com.br. 
International Classification of Functioning, Disability and Health — it was developed a documentary study in which 1,404 application forms for the Continued Benefit for disabled people from May, 2006 to April, 2012 were submitted to a statistical descriptive analysis. The results showed that the exclusion structure has been kept with the adopted evaluation, as well as the restrictiveness to the Continued Benefit for disabled people.

Keywords: Social Security medical evaluation. Social evaluation of disability. Social protection.

\section{Introdução}

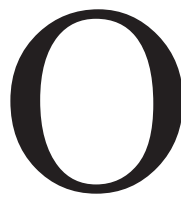

Benefício de Prestação Continuada (conhecido como BPC/Loas ou simplesmente BPC) tem um papel importante na construção da política social, atendendo, em todo o Brasil, a 3.999.462 pessoas, sendo que, desse total, mais de 2 milhões são PcDs e mais de 1,7 milhões, de idosos acima de 65 anos (Brasil, 2012).

Pelo critério de gastos públicos, o BPC é o maior no contexto brasileiro, de modo que o somatório de todos os benefícios pagos no Brasil alcançou, em valor corrente, o patamar de R \$27,8 bilhões, em 2012 e, para este ano, tem orçamento previsto de $\mathrm{R} \$ 30,5$ bilhões, quase $50 \%$ acima dos $\mathrm{R} \$ 23,9$ bilhões que o maior programa de transferência de renda para famílias beneficiadas — o Programa Bolsa Família (PBF) — repassará este ano. O BPC destaca-se como o programa na área social de maior desembolso do governo federal, representando 86,21\% do Fundo Nacional da Assistência Social (FNAS), apesar de o Bolsa Família configurar como o maior programa social em termos de cobertura (13,5 milhões de famílias ou cerca de 50 milhões de pessoas) (Brasil, 2013).

A revisão da literatura indicou que o BPC tem-se constituído em objeto de estudo, não apenas para profissionais afetos à política de assistência social, mas, para diversas áreas do conhecimento como as das ciências econômicas, sociologia e direito, suscitando discussão numa dimensão interdisciplinar. No período entre 2007 e 2011, foram produzidas significativas contribuições para o entendimento da temática, especialmente sobre conceitos e critérios adotados pelo BPC, bem como sobre a importância do benefício como mecanismo para proteção social, apesar de uma parcela considerável não ter seus direitos garantidos. Em todo o material revisado, ganham relevo o campo do direito social, a 
judicialização, a alteração nos conceitos de família e de deficiência e os critérios de elegibilidade, com destaque para o critério de renda.

No entanto, são raras as temáticas ligadas à avaliação social e, principalmente, à influência destas no resultado de concessão do BPC. Da mesma forma, permanecem lacunas nos conhecimentos a respeito da necessidade de estudos sobre o conceito de incapacidade para o trabalho (Diniz et al., 2007); da avaliação sobre as informações mais recentes sobre o tamanho e distribuição do programa entre os estratos sociais (Medeiros et al., 2009); lacunas referentes, também, à escassez de dados que não permite estimar com precisão os custos que o aumento na renda per capita podem gerar (Penalva et al., 2010); à ausência de pesquisas de avaliação e monitoramento do BPC; referentes, ainda, aos impactos deste benefício sobre a vida das pessoas atendidas versus mercado de trabalho para pessoas pobres e deficientes; aos estudos sobre os cuidadores das pessoas com deficiência (Santos, 2011) e à necessidade de estudos acerca do instrumento de avaliação para compreender em que medida as alterações conceituais promovidas pelo Decreto Federal n. 6.214/2007, que integrou a dimensão social na avaliação do BPC da pessoa com deficiência, estaria contribuindo para ampliar o acesso ao reconhecimento inicial do direito da pessoa com deficiência (Ivo e Silva, 2011).

Nesta direção, o presente artigo propõe-se identificar e analisar os resultados do processo de avaliação das pessoas com deficiência (PcDs) requerente do BPC, após a implantação do modelo de avaliação, baseado na Classificação Internacional de Funcionalidade, Incapacidade e Saúde (CIF). Para tanto, revisita os marcos da constituição do processo saúde-doença e trabalho e sinaliza um breve histórico sobre a perícia médica previdenciária. Na sequência, aponta as alterações na forma de avaliação e finaliza com a discussão sobre como estas alterações se desenvolveram na Agencia da Previdência Social (APS) de Assis Chateaubriand.

\section{BPC e perícia médica previdenciária: algumas consideraç̃ões}

O BPC é um benefício individual, não vitalício e intransferível que se caracteriza pela transferência monetária mensal, no valor de um salário míni- 
mo, aos beneficiários idosos (65 anos ou mais) ou às PcDs incapacitadas para o trabalho e para a vida independente, cuja renda familiar mensal per capita seja inferior a $1 / 4$ do salário mínimo. Não é condicionado a qualquer contrapartida, bem como independe de contribuições prévias para o sistema de seguridade social.

Como disposto no inciso V, do artigo 203, da Constituição Federal de 1988 (CF/88), o BPC encontra-se regulamentado desde 1993, através do artigo 20, da Lei Orgânica da Assistência Social (LOAS) — Lei n. 8.742/1993, e em funcionamento desde 1996. A gestão do BPC é realizada pelo Ministério do Desenvolvimento Social e Combate à Fome (MDS), por intermédio da Secretaria Nacional de Assistência Social (SNAS), que é a responsável pela implementação, coordenação, regulação, financiamento, monitoramento e avaliação. A operacionalização do BPC fica a cargo do INSS e os recursos para seu custeio provêm do FNAS (Brasil, 2007b).

O BPC é o único direito de proteção social não contributivo que foi efetivado após a promulgação da $\mathrm{CF} / 88$. No entanto, dado o esfacelamento das proteções sociais como um todo, no contexto do neoliberalismo, sua concretização esbarra na muralha da burocracia. $\mathrm{O}$ ingresso a este direito constitucional está relacionado aos critérios fastidiosos de seleção que corroem o progresso constitucional, pois limitam o direito do cidadão à renda per capita familiar e à prova de incapacidade para a vida independente e para o trabalho.

Uma das polêmicas no processo de implementação, até hoje, e um dos elementos de tensão é a adequação de um mecanismo para a comprovação da incapacidade. A comprovação da deficiência, no primeiro ano, era realizada por uma equipe multiprofissional, mas, com a edição da Medida Provisória n. 1.473/1997, em agosto de 1997, passa a ser uma atribuição exclusiva da Perícia Médica do INSS, desconsiderando a perspectiva proporcionada pela avaliação multidisciplinar. Pela inadequação do modelo biomédico e para atender às reivindicações de segmentos envolvidos com a temática, após um longo processo, foi sancionado o Decreto Federal n. 6.214/2007, que determinou novo modelo de avaliação. O Decreto prevê, entre outras questões, que o acesso ao BPC deva ser efetuado após a aplicação de um instrumental denominado de Avaliação Médica e Social, que tem como base a CIF. Porém, mesmo estabelecido em lei desde 2007, somente a partir de maio de 2009 é que esta prática começa a ser realizada pelo INSS. 
Para a compreensão sobre como esta prática vem sendo realizada, faz-se necessário um retrocesso histórico sobre a constituição da perícia médica previdenciária. E é o que se quer destacar na sequência, apontando-se para como era realizada a avaliação da pessoa com deficiência elegível ao benefício e as alterações que ocorreram nas legislações, tendo como resultado a introdução do novo modelo de avaliação da deficiência para acesso ao benefício.

\subsection{Considerações acerca do processo de saúde-doença e trabalho}

O século XIX foi marcadamente o século da transformação da natureza do trabalho. A chamada Revolução Industrial impulsionou o desenvolvimento em todas as áreas. Porém, esta civilização do trabalho trouxe como consequência o surgimento de novas implicações e agravos para a saúde. O homem, agora essencialmente trabalhador e urbano, passou a ser exposto a diferentes acidentes ligados ao trabalho e às doenças de natureza ocupacional (Oliveira, 2001).

Como apontam Mendes e Dias (1991), o conhecimento técnico sobre estes novos agentes agressivos, sua forma de ação, consequências e tratamentos, foram pouco a pouco sendo desvendados pela ciência, e um novo campo da medicina surgiu em função dessas relações visando o controle da força de trabalho para o aumento da produtividade: a Medicina do Trabalho (MT). O objetivo da MT era o de trazer o funcionário rapidamente de volta ao trabalho, exercendo uma medicina curativa, constituindo-se em serviço dirigido por pessoas de inteira confiança do empresário e dispostas a defendê-lo, e em tarefa eminentemente médica, a prevenção e a responsabilidade pela ocorrência dos problemas de saúde resultantes dos riscos do trabalho. Neste sentido, os médicos buscavam uma adaptação dos trabalhadores às máquinas e aos meios de trabalho, num contexto de péssimas condições de trabalho, em que, estes últimos, frequentemente adoeciam e até mesmo morriam.

Após a Segunda Guerra Mundial, as indústrias cresceram e as condições de trabalho pioraram. Inicia-se então um movimento de insatisfação e de questionamentos por parte de empregadores e empregados sobre as condições ambientais e o adoecimento advindo do trabalho penoso, que onerava patrões, 
seguradoras e deixava trabalhadores sequelados. A atuação dos serviços da Medicina do Trabalho, centrada na figura do médico, mostrou-se insuficiente para atender os problemas como os do adoecimento do trabalhador. Desta forma, surge o modelo de intervenção sobre o ambiente, a Saúde Ocupacional (SO), tendo como principal estratégia a intervenção nos locais de trabalho através da atuação multiprofissional, com a finalidade de controlar os riscos ambientais (Mendes e Wunsch, 2011).

Entretanto, o modelo da SO não conseguiu atingir os seus objetivos, por manter o referencial sobre indivíduos - ao privilegiar o diagnóstico e o tratamento dos problemas de natureza orgânica e incorporar práticas e conhecimentos da clínica, medicina preventiva e epidemiologia clássica, mediante a história natural da doença para a análise das doenças e acidentes do trabalho — sustentado pela tríade "agente-hospedeiro-ambiente".

Derivada da informação restrita e da atuação autoritária dos profissionais de saúde, no trabalho ou fora dele, a SO contribui, com isso, para a alienação e desinformação do trabalhador, deixando pouco espaço para sua subjetividade. Essa prática confere, ainda, maior capacidade de controle do capital sobre o trabalho, impedindo que se considere e opere sobre nexos mais complexos, pois toma o trabalhador como paciente passivo e hospedeiro, objeto da técnica, estreitando a possibilidade de apreensão e pouco contribuindo para a compreensão da causalidade das doenças relacionadas ao trabalho na contemporaneidade (Lacaz, 2007).

A partir do final dos anos de 1960, em meio a um intenso processo de mudanças sociais, surgem críticas e questionamentos ao modelo da SO. Uma forma distinta de analisar as questões referentes ao trabalho-saúde/doença surge com alguns autores da Medicina Social Latino-americana, entre os quais, Laurell e Noriega (1989), que conceituam o trabalho a partir da concepção de processo de trabalho inscrita nas relações sociais de produção. Assim, além das consequências mais visíveis do trabalho sobre a saúde, quais sejam, as dos agentes nocivos de natureza química, física, entre outros, procuram também entender a nocividade do trabalho com suas implicações no nível biopsíquico.

No Brasil, a emergência da Saúde do Trabalhador (ST), enquanto marco teórico, pode ser identificada na década de 1980, tendo sido estabelecida na CF/88 e, posteriormente, regulamentada e definida com a Lei Orgânica da 
Saúde (LOS) - Lei n. 8.080/90. A ST diferencia-se e opõe-se aos modelos hegemônicos das práticas de intervenção e regulação das relações saúde-trabalho tradicionais. Esta abordagem busca resgatar o lado humano do trabalho e sua capacidade protetora de agravos à saúde dos trabalhadores. Na medida em que as classes trabalhadoras constituem-se em novo sujeito político e social, apreendendo-o como agente de mudanças e como ator histórico, com saberes e vivências sobre seu trabalho, compartilhadas coletivamente, ele pode intervir e transformar a realidade do trabalho, participando do controle da nocividade, da definição consensual de prioridades de intervenção e da elaboração de estratégias transformadoras (Lacaz, 2007).

Convém ressaltar que as três formas de abordagem da relação entre trabalho e processo saúde-doença coexistem na atualidade, configurando um embate que reflete de alguma forma o embate social, pois suas práticas situam-se no campo do conflito do capital/trabalho. E como todo embate é constituído de avanços e retrocessos, a história atual tem explicitado que o estabelecimento de diretrizes dessa política, por parte dos trabalhadores, já não é tão observada. Conforme Lacaz (2007), a realidade vivida em função da fragilidade atual dos movimentos sociais, da nova configuração do mundo do trabalho, aliada à postura pouco engajada da academia e ao desenvolvimento de políticas públicas reducionistas, constrói um quadro de retrocesso no campo da ST que é preciso combater.

Essa ressalva é necessária, pois como se verá a seguir, no âmbito da previdência social brasileira não se revela protagonismo de ações de prevenção de doenças e/ou promoção de saúde que correspondam à intervenção sobre fatores extrabiológicos; ou seja, não se atende à perspectiva de atuação que compreenda o processo saúde-doença a partir da discussão do campo da Saúde do Trabalhador. Ao contrário, observa-se uma hegemonia do discurso da Saúde Ocupacional e da Medicina do Trabalho, para as quais a lógica de atribuição de culpa confere ao trabalhador a responsabilidade pelo adoecimento do qual é vítima (Pinto Júnior et al., 2012).

Centrados na figura do médico, na concepção de multicausalidade da doença, entendida como decorrente de um processo biológico e da exposição a fatores de riscos, as avaliações médicas periciais desconsideram a natureza social do processo saúde e doença, como exposto a seguir. 


\subsection{Considerações sobre perícia médica previdenciária}

A perícia médica previdenciária tem por finalidade subsidiar a autoridade administrativa do INSS acerca de características constatáveis no requerente a benefícios assistenciais ou previdenciários, que lhe permita reconhecer ou não o direito previsto em lei.

Como bem ressalta Almeida (2011), a perícia médica previdenciária consiste eminentemente em caracterizar a presença ou ausência de incapacidade laboral, não havendo relação médico-paciente com pressupostos da confiança mútua; é nela, mais provável, que as manifestações de distanciamento e autoritarismo estejam potencializadas.

Melo e Brant (2005) referem que não raro são falas dos segurados as de que a sala de perícia é local de tortura emocional, em que prevalece não o social e a dignidade da pessoa humana, mas o interesse patrimonialístico, com a relação médico-paciente constituída pelas categorias: submissão, conflito e resistência, apresentando-se o segurado, evidentemente, como a parte mais fraca desta relação. Paralelamente, desconsideram-se elementos fundamentais na gênese do acidente ou adoecimento, como a pressão por produção, as horas extras, as ameaças de demissão, os prêmios por produtividade, a distância e as dificuldades de acesso entre residência e emprego, baixos salários, busca por outras fontes de renda e preocupação com situações pessoais ou familiares, entre outras.

Para Junior (2011), a incapacidade, em qualquer sentido, constitui julgamento, haja vista não existir como conceito de per si, mas sempre relacionado a alguma habilidade; cabe ao perito verificar se o conceito se aplica ao caso concreto que analisa, ou seja, se transcende o diagnóstico nosológico principal e leva em conta outras comorbidades, aspectos sociais e crenças pessoais e ideológicas do próprio perito médico. Desta maneira,

Ainda que os médicos sejam os profissionais autorizados pela sociedade para definir quem está ou não doente e definir as causas do adoecer, não se pode desconsiderar que a análise do diagnóstico é também influenciada pela formação técnica e pelas conviç̧ões pessoais do profissional. (Murofuse, 2004, p. 167) 
E, por mais que alguns profissionais queiram visualizar o trabalhador como um todo e situá-lo, de alguma maneira, no seu contexto socioeconômico, terminam por regressar ao reducionismo, pois este foi o modelo em que foi pautada sua formação na escola médica (Barros, 2002).

A lógica que rege o ato médico-pericial previdenciário é o conceito de incapacidade laborativa que, conforme Gomes (2009), seria a impossibilidade temporária ou definitiva do desempenho das funções específicas de uma atividade ou ocupação, em consequência de alterações morfopsiquicofisiológicas provocadas por doença ou acidente, para a qual o examinado estava previamente habilitado e em exercício. O risco de vida para si ou para terceiros, ou o agravamento que a permanência em atividade possa acarretar, está implicitamente incluído no conceito de incapacidade, desde que palpável e indiscutível. Mais especificamente, a capacidade laborativa implica na relação de equilíbrio entre as exigências de uma dada ocupação e a capacidade para realizá-las. A incapacidade deve ser analisada quanto ao grau (parcial ou total), à duração (temporária ou permanente) e à profissão desempenhada (uniprofissional, multiprofissional ou omniprofissional).

Para atender às expectativas do ato médico, o perito previdenciário deveria ser um profissional com conhecimento necessário das leis, normas, portarias, profissiografia, além de ter capacidade de avaliar a associação das patologias à atividade do trabalhador e a todos os fatores associados à sua capacidade laborativa. Deveria, outrossim, somar, à necessidade de uma sólida formação clínica, amplo domínio da legislação, disciplina legal e administrativa, além de possuir atributos de caráter e personalidade (integridade, independência, equilíbrio). Mas, o que se evidencia na história da previdência social em relação à perícia médica previdenciária, embora possa haver algumas exceções, é a negação da relação com o trabalho. Desconsideram inclusive o que relatam os trabalhadores sobre seus sintomas, valorizando extremamente apenas os aspectos biológicos do corpo do trabalhador, que sejam visíveis (sinais e não sintomas) e, de preferência, comprovados por exames (exames esses que, em vez de serem tratados como complementares, são tomados como decisivos em muitos casos), não respeitando o sujeito social/trabalhador, mas uniformizando os procedimentos para o atendimento ao regime capitalista de produção (Brasil, 2005). 
A explicação para esta não valorização do trabalhador como sujeito ativo do processo saúde-doença pode estar nas bases históricas, sob as quais foi construída a perícia médica previdenciária, o que dificulta, e mesmo impede, sua efetivação, pois migrar dos paradigmas que norteavam a definição centrada na doença e suas consequências, para uma práxis que privilegie a saúde, importa em longo percurso, ou quase uma conversão, visto ainda não ter sido totalmente incorporado à prática cotidiana.

\subsection{Avaliação da PcD para acesso ao BPC: da concepção biomédica para os determinantes sociais do processo saúde-doença}

Por ser o BPC operacionalizado pelo INSS, por muito tempo o mesmo foi percebido como benefício previdenciário, e não assistencial, distanciando-se de seus objetivos tais como a efetivação de um direito de proteção social para pessoas que, por incapacidades de algum tipo, experimentavam situações de vulnerabilidade econômica e social.

Sua concessão, realizada exclusivamente pela perícia médica do INSS, enfrentava as dificuldades já elencadas, por estar inserida numa lógica previdenciária que avaliava a deficiência numa perspectiva individual, utilizando-se de critérios biologicistas. O biologicismo, ao pressupor o reconhecimento da natureza biológica das doenças, se justifica pela compreensão de que a doença é causada por agentes biológicos (aí incluídos os químicos e físicos), em corpos biológicos e com repercussão biológica. Por conseguinte, focaliza a avaliação e o tratamento nos sinais e nos sintomas, valorizando sobremaneira a entidade estrutural patológica. Deste modo, associa-se à unicausalidade, conferindo uma dimensão estritamente biológica ao ser humano, descontextualizando-o de sua posição biográfica, familiar e social.

Dentre os argumentos para tentar justificar o predomínio do modelo médico nas avaliações dos requerentes ao BPC, o mais comum é o de que os médicos peritos são os mais preparados para avaliar o aspecto laborativo da pessoa, para fins de concessão de benefícios trabalhistas. Com isto, a elegibilidade da PcD para o BPC acabou se sujeitando a essa prática recorrente de uma 
avaliação mais restritiva e desconsiderando outros aspectos relevantes para a avaliação da deficiência (Sposati, 2004).

Esse modelo médico de avaliação que considera a deficiência como atributo da pessoa - sem considerar outras dimensões presentes no estado de saúde e a partir da visão individual e subjetiva do avaliador e o insuficiente grau de uniformização - fez com que se intensificasse a insatisfação da sociedade quanto à forma como a avaliação do BPC era realizada (Brasil, 2007b).

Assim, de forma a minimizar os problemas advindos da avaliação da perícia médica, o Governo Federal instituiu, em 2005, um Grupo de Trabalho Interministerial (GTI), formado por técnicos do MDS e do Ministério da Previdência Social (MPS), visando à proposição de novos parâmetros de avaliação das PcDs solicitantes ao BPC, capazes de diminuir o nível de subjetividade do procedimento e que considerasse a incapacidade não apenas como um atributo da pessoa, mas como consequência de um conjunto complexo de situações de natureza biológica, individual, econômica e social. Esse grupo propôs, então, uma avaliação baseada na CIF (Brasil, 2007b).

A CIF, publicada pela Organização Mundial de Saúde (OMS), em 2001, é considerada um marco no debate sobre deficiência e foi adotada por diversos organismos nacionais e internacionais, sendo aceita por 191 países como a nova norma internacional para descrever e avaliar a saúde e a deficiência. A CIF é propícia para aplicação em vários aspectos da saúde e o documento que a institui, caracteriza-se como uma revisão da International Classification of Impairments, Disabilities, and Handicaps (ICIDH), primeira tentativa da OMS de organizar uma linguagem universal sobre lesões e deficiências, publicada em 1980; a ICDH2 foi publicada em 1998.

A CIF apresenta um conceito de deficiência como interrelacional e descreve o corpo em uma abordagem biopsicossocial. Esse modelo foi adotado no Brasil, em 2007, por meio da legislação que dá suporte ao BPC. A CIF não é um instrumento de avaliação, mas, sim, um quadro de referência para a formulação, reformulação e construção de instrumentos de avaliação. Como sistema de classificação e de codificação, a CIF é um meio para documentar e organizar a informação que se torna relevante para descrever a natureza e a severidade das limitações funcionais da pessoa, as suas experiências de vida bem como as características do meio circundante (Brasil, 2007b). 
A CIF e o Código Internacional de Doenças Décima Revisão (CID-10) são complementares entre si, pois a CID-10 fornece um "diagnóstico" de doenças, distúrbios ou outras condições de saúde, e essas informações são complementadas pelos dados adicionais fornecidos pela CIF sobre funcionalidade. Ao ampliar o entendimento sobre a deficiência, abordando-a como limitação que interfere na autonomia do indivíduo nos múltiplos espaços sociais, a adoção do modelo de avaliação baseado na CIF poderia reforçar a proteção social das pessoas com deficiência.

Este modelo foi, então, regulamentado através do Decreto n. 6.214, de 26 de setembro de 2007, instituindo-se os instrumentos baseados na CIF para avaliação da deficiência e do grau de incapacidade da $\mathrm{PcD}$ requerente ao BPC, e iniciou-se a sua implementação, pelo INSS, em junho de 2009, ou seja, dois anos após a sua instituição legal. O modelo proposto pela CIF baseia-se na junção dos modelos médico e social, e em uma abordagem biopsicossocial usada para se obter uma integração das várias dimensões da saúde (biológica, individual e social). A funcionalidade e a incapacidade humanas são concebidas como uma interação dinâmica entre as condições de saúde (doença, trauma, lesões, distúrbios) e os fatores contextuais (incluindo fatores pessoais e ambientais).

Atualmente, para requerer o BPC, a PcD procura uma das Agências do INSS, preenche os formulários de solicitação do benefício e de declaração de renda dos membros da família, acompanhados de documentos comprobatórios de renda e residência. Após a habilitação inicial, é realizada a avaliação social por assistente social e, em seguida, a avaliação médica para definição da deficiência e do grau de incapacidade.

A avaliação social objetiva apreciar os fatores ambientais e o impacto no desempenho da atividade e na participação social da pessoa avaliada e, por isso, incumbe-se das relações de convívio familiar, comunitário e social, em que se avaliam a acessibilidade às políticas públicas, a vulnerabilidade e o risco pessoal e social a que a PcD está submetida, e as características do ambiente físico — território onde vive e as condições de vida presente — tais como acessibilidade, salubridade ou insalubridade. Já a avaliação médico-pericial analisa a deficiência em relação à função do corpo e seu impacto no desempenho da atividade e na participação do requerente, divididas em oito, nove e cinco domínios, respectivamente. A função do corpo inclui a avaliação das funções: 
mentais; sensoriais; da voz e da fala; dos sistemas cardiovascular, hematológico, imunológico e respiratório; dos sistemas digestivo, metabólico e endócrino; geniturinárias; neuromusculoesqueléticas e relacionadas ao movimento; e da pele. Quanto à atividade e participação, avaliam-se, também, os seguintes domínios: aprendizagem e aplicação do conhecimento; tarefas e demandas gerais; comunicação; mobilidade e cuidado pessoal (Brasil, 2007b).

As avaliações contêm "qualificadores", que são códigos especificadores da extensão ou da magnitude do comprometimento da funcionalidade, da extensão ou magnitude da dificuldade no desempenho de uma atividade e tarefa, e da extensão na qual um fator ambiental é uma barreira. O qualificador para deficiência, dificuldade ou barreira variará de nenhuma limitação à extrema limitação, sendo estes determinados em escala ordinal de 0 a 4 pontos (nenhu$\mathrm{ma}=0$, leve $=1$, moderada $=2$, grave $=3$ ou completa $=4)($ Brasil, 2007b).

Ao final, para se avaliar se o requerente apresenta evidências de incapacidade para a vida independente e para o trabalho, consideram-se as informações da avaliação social e médico-pericial e os intervalos quantitativos, em percentuais, que denotarão a extensão da deficiência das funções do corpo, da dificuldade das atividades e participação, e das barreiras dos fatores ambientais (Brasil, 2007b).

Levando-se em conta essa dinâmica e a interdependência dos saberes na instituição do processo de avaliação social e médico-pericial baseado na CIF, foram previstos momentos de interação/diálogo entre os profissionais, médico e assistente social, para decisões consensuais sobre a pontuação dos qualificadores. No entanto, na prática, estes momentos não ocorrem, pois ao final da avaliação médico-pericial, o próprio sistema operacional conclui o laudo através de uma tabela de combinações que prevê os possíveis resultados da avaliação dos três componentes e informa sobre o deferimento ou indeferimento.

\section{A avaliação do processo, na APS de Assis Chateaubriand}

O suporte ao estudo foi dado pela pesquisa documental, tendo, como local da coleta de dados, a Agência da Previdência Social (APS), de Assis Chateaubriand, Paraná. Foram analisados 1.404 BPCs para PcDs, requeridos no período 
de maio de 2006 a abril de 2012, na faixa etária de 20 a 65 anos de idade, na data de entrada do requerimento. A coleta de dados foi realizada por meio de consultas on-line provenientes de quatro sistemas ${ }^{1}$ do INSS, complementadas por meio de consulta manual dos processos arquivados na APS. O instrumento de coleta utilizado foi validado através de um pré-teste aplicado ao grupo de requerentes, menores de 20 anos de idade.

As informações coletadas foram organizadas em planilhas eletrônicas, utilizando-se o programa Excel 97-2003. Foi realizada análise estatística descritiva simples, apresentando-se os resultados por meio de distribuição de frequência (absoluta e percentual). Para fazer a comparação entre ANTES e DEPOIS, foi utilizado o Teste Quiquadrado $\left(\mathrm{c}^{2}\right)$ de associação e, para levantar crescimento ou decréscimo, utilizou-se a Fórmula da Taxa de Crescimento: $(\mathrm{t} 1 / \mathrm{t} 0)-1 \times 100$. Neste estudo, que teve a ética como referencial, procedeu-se à coleta somente após a aprovação do projeto de pesquisa (Parecer n. 041/2012) pelo Comitê de Ética em Pesquisa, da Universidade Estadual do Oeste do Paraná (Unioeste).

Do total de 1.404 requerimentos de BPC para PcD, 643 foram referentes ao período de maio de 2006 a abril de 2009, anterior à implantação do modelo de avaliação baseado na CIF, e outros 761 requerimentos correspondentes ao período de maio de 2009 a abril de 2012, após a implantação do modelo de avaliação vigente (Decreto Federal n. 6.214/2007). Destes últimos, obteve-se maioria de indeferidos ( 815 benefícios), correspondentes a 58,05\% do total; a minoria, (589) de deferidos, representou $41,95 \%$ dos requerimentos entre 2009/2012 (ou segundo período).

Ao utilizar-se o Teste Quiquadrado, o resultado do $p$-valor foi de 0,4237 , indicando que as concessões e os indeferimentos, nos dois períodos pesquisados equivaleram-se, conforme apresentado no Gráfico 1.

Observa-se na Tabela 1, que houve um acréscimo de 18,35\% no número de requerimentos depois de instituído o Decreto n. 6.214/2007. O número de benefícios deferidos $(43,85 \%)$, no primeiro período, foi maior em relação ao

1. São eles: Sistema Único de Informações de Benefícios (SUIBE), Sistema de Administração de Benefícios por Incapacidade (SABI), Sistema de Avaliação do Benefício de Prestação Continuada para pessoa com deficiência (SIAVBPC) e Cadastro Nacional de Informações Sociais — Pessoa Física (CNISPF). 
segundo período $(40,34 \%)$ e, inversamente, os indeferidos menores no primeiro período $(56,14 \%)$ em relação ao segundo período $(59,65 \%)$, apontando para um decréscimo de $8 \%$ nos deferimentos e um acréscimo de $6,25 \%$ nos indeferimentos nos períodos analisados.

Gráfico 1. Evolução do BPC para PcD requeridos na APS de Assis Chateaubriand, no período de maio de 2006 a abril de 2012

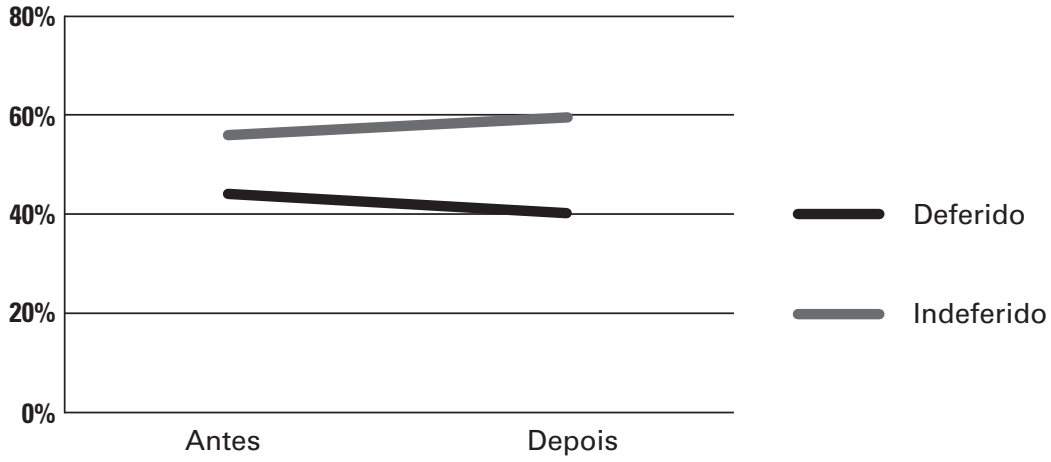

Fonte: Suibe INSS.

Tabela 1. Distribuição dos requerimentos deferidos e indeferidos de BPC para PcD, segundo o período - Assis Chateaubriand, PR

\begin{tabular}{|c|c|c|c|c|c|c|}
\hline \multirow{2}{*}{ Situação } & \multicolumn{2}{|c|}{ Antes* $^{*}$} & \multicolumn{2}{c|}{ Depois** $^{*}$} & \multicolumn{2}{c|}{ Total } \\
\cline { 2 - 7 } & N & $\%$ & N & $\%$ & N & $\%$ \\
\hline Deferido & 282 & 20,08 & 307 & 21,87 & 589 & 41,95 \\
\hline Indeferido & 361 & 25,71 & 454 & 32,34 & 815 & 58,05 \\
\hline Total & 643 & 45,79 & 761 & 54,21 & 1.404 & 100,00 \\
\hline
\end{tabular}

Fonte: Suibe INSS. Elaboração própria.

$\mathrm{N}$ : número. \%: percentagem.

* Antes: maio de 2006 a abril de 2009.

** Depois: maio de 2009 a abril de 2012. 
Os resultados obtidos não estão em consonância com os resultados obtidos em nível nacional, pois de acordo com a Nota Técnica DBA/SNAS/MDS n. 69, de 2010, a análise dos despachos dos requerimentos de BPC à pessoa com deficiência, concentrada nos períodos anterior e posterior à implantação do novo modelo, indicou que houve aumento significativo no número de concessões do benefício, atingindo 26,5\%, acompanhado de um decréscimo de $11,91 \%$ nos indeferimentos. A nota aponta, ainda, a tendência de crescimento da concessão do benefício observada em quase todos os Estados do Brasil, exceto nos do Amapá e de Tocantins, com diminuição nos índices de deferimento (Brasil, 2010).

Destoando das indicações de crescimento nas concessões de benefícios, os resultados encontrados no presente estudo (Tabela 1) apontam para a restrição e, portanto, para a não ampliação do acesso ao reconhecimento desse direito, com o uso do modelo de avaliação baseado na CIF. Santos (2010) refere que a adoção da CIF pode ser considerada um avanço na orientação da avaliação das condições que transformam as pessoas deficientes em elegíveis ao BPC, pela agregação das ideias do modelo social, porém, ela não altera os parâmetros da incapacidade para o trabalho e para a vida independente assinalado na Loas. De acordo com o Decreto n. 6.214/2007, artigo $4^{\circ}$, designa-se pessoa com deficiência, aquela "cuja deficiência a incapacita para a vida independente e para o trabalho" (Brasil, 2007a) e, por incapacidade entende-se "um fenômeno multidimensional que abrange limitação de desempenho de atividade e restrição da participação, com redução efetiva e acentuada da capacidade de inclusão social, em correspondência à interação entre pessoa com deficiência e seu ambiente físico e social" (Brasil, 2007a).

A CIF apresenta uma concepção ampliada do processo saúde-doença, o que permitiria, se aliada a outras metodologias, um desenho aproximado da concepção da determinação social do processo saúde-doença. ${ }^{2}$ No entanto, pela análise do modelo de avaliação proposto pelo INSS, e baseado na CIF, observam-se ausências que indicam o predomínio da visão hegemônica, segundo a qual

2. Determinação social significa ampliação do quadro interpretativo do processo saúde-doença, ultrapassando articulações simplificadas e reducionistas entre causa e efeito, sustentadas por uma visão monocausal (doença e um agente específico) ou multicausal (entre doença e um grupo de fatores de risco) presentes no ambiente de trabalho, incluindo aí a dimensão de "classe" e a categoria "trabalho" entre os determinantes sociais. 
o entendimento ainda recai sobre os determinantes do processo saúde-doença e não apresenta as iniquidades em saúde como produto das desigualdades sociais e nem reafirma o papel do Estado para superá-las.

A inclusão de dimensões não centradas exclusivamente em problemas biomédicos aparentemente tornou mais complexa a avaliação das PcDs requerentes do BPC. Este instrumental ajudou a dar maior relação de objetividade diante de um direito reclamável judicialmente, visto que o BPC constitui-se numa medida de proteção social, não contributiva, dentro do Sistema Único de Assistência Social e que tem no beneficiário um público-alvo prioritário para acesso a todas as demais políticas de educação, saúde, habitação, entre outras.

Ao analisar o total dos requerimentos indeferidos nos períodos estudados, observa-se por meio da Tabela 2, que a renda, como categoria isolada e na comparação entre os períodos, constituiu-se no principal motivo dos indeferimentos $(31,17 \%)$. Mas, ao considerar o conjunto de indeferimentos pela não constatação da incapacidade, ${ }^{3}$ o percentual de indeferidos salta para $61,96 \%$ dos requerimentos nos períodos estudados. A gravidade da situação pode ser estimada quando se considera que as pessoas eram deficientes e pobres, enquadrando-se, assim, dentro dos princípios da preservação da vida e da dignidade da pessoa humana que nortearam a proposta da proteção social não contributiva, prevista na CF/88, como nos ensina Sposati (2009).

Cabe ressaltar que, em relação aos requerimentos protocolados no período anterior à instituição da avaliação baseada na CIF, houve um percentual de $26,26 \%$ de indeferimentos pelo motivo de parecer contrário da perícia médica. E, após a inclusão da avaliação social, o índice de indeferidos por não haver incapacidade saltou para $35,70 \%$, evidenciando uma tendência à não observação dos fatores contextuais na avaliação da PcD, conforme preconizado na CIF e, reduzindo, com isso, a avaliação a uma análise individualizada, sem a compreensão do requerente no contexto social.

3. Para propósitos estatísticos, as categorias: parecer contrário da perícia médica, deficiência temporária e não há incapacidade para vida independente e para o trabalho, foram consideradas segmentos da mesma espécie, pois, nestas, o indeferimento deu-se a partir da constatação da não incapacidade para a vida independente e para o trabalho, as quais são observadas através da avaliação médico-pericial e, após a implantação do Decreto n. 6.214/2007, também através da avaliação social. 
Tabela 2. Distribuição dos requerimentos indeferidos de BPC para PcD, segundo o motivo e período - Assis Chateaubriand, PR

\begin{tabular}{|l|c|c|c|c|c|c|}
\hline \multirow{2}{*}{ Motivo } & \multicolumn{2}{|c|}{ Antes* } & \multicolumn{2}{c|}{ Depois** } & \multicolumn{2}{c|}{ Total } \\
\cline { 2 - 7 } & N & $\%$ & N & $\%$ & N & $\%$ \\
\hline Deficiência temporária & - & - & 100 & 12,27 & 10 & 12,27 \\
\hline $\begin{array}{l}\text { Não comparecimento para } \\
\text { realização de exame } \\
\text { médico-pericial }\end{array}$ & 11 & 1,35 & 28 & 3,44 & 39 & 4,79 \\
\hline $\begin{array}{l}\text { Não comparecimento para } \\
\text { avaliação social }\end{array}$ & - & - & 1 & 0,12 & 1 & 0,12 \\
\hline $\begin{array}{l}\text { Não cumprimento de } \\
\text { exigência }\end{array}$ & 8 & 0,98 & 3 & 0,37 & 11 & 1,35 \\
\hline $\begin{array}{l}\text { Não há incapacidade para } \\
\text { vida independente e para o } \\
\text { trabalho }\end{array}$ & - & - & 191 & 23,43 & 191 & 23,43 \\
\hline $\begin{array}{l}\text { Parecer contrário da } \\
\text { perícia médica }\end{array}$ & 214 & 26,26 & - & -128 & 214 & 26,26 \\
\hline $\begin{array}{l}\text { Renda per capita familiar } \\
>=1 / 4 \text { sal. mín. DER }\end{array}$ & 126 & 15,46 & 128 & 15,71 & 254 & 31,17 \\
\hline Sem informação & 2 & 0,24 & 3 & 0,37 & 5 & 0,61 \\
\hline Total & 361 & 44,29 & 454 & 55,71 & 815 & 100,00 \\
\hline
\end{tabular}

Fonte: Suibe, Sabi INSS. Elaboração própria.

$\mathrm{N}$ : número. \%: percentagem.

$>=1 / 4$ : renda per capita maior ou igual a um quarto de salário mínimo na data de entrada do requerimento.

* Antes: maio de 2006 a abril de 2009.

** Depois: maio de 2009 a abril de 2012.

O uso do instrumental de avaliação, portanto, não tem contribuído para o alcance da plena finalidade almejada pela $\mathrm{CF} / 88$; ao contrário, tal regulamentação favoreceu ainda mais a forma seletiva, restritiva e arbitrária de averiguação, excluindo muitos deficientes e pobres do acesso ao benefício. Conclui-se 
assim que o modelo de avaliação vigente não pode ser considerado um canal para ampliar direitos, pois os itens que compõem o instrumental de avaliação social e médico-pericial estão postos de forma fechada e predeterminada, com avaliadores seguindo um roteiro bastante rígido e extremamente burocrático, que tenta, por meio da suposta objetividade e neutralidade possível, construir elementos para negar a exigência de um direito também pela via judicial.

\subsection{Impedimentos de longo prazo}

O Brasil segue a Convenção Internacional sobre os Direitos das Pessoas com Deficiência ${ }^{4}$ nas normatizações sobre a deficiência. No entanto, a Lei n. 12.435/2011, ao alterar o artigo $20, \S 2^{\circ}$, da Lei n. 8.742/1993, em seu inciso II, e estabelecer como impedimentos de longo prazo "aqueles que incapacitam a pessoa com deficiência para a vida independente e para o trabalho pelo prazo mínimo de 2 (dois) anos", restringiu o conceito constitucional de deficiência ao dispor sobre prazo não previsto na Convenção ratificada pelo Brasil.

O artigo de proteção social da Convenção não especifica que impedimentos de longo prazo serão elegíveis à proteção social. O texto da Convenção - ou melhor, o conceito de deficiência da Constituição Federal — não reduz direitos fundamentais à duração de impedimentos corporais; ao contrário, mantém a proteção social no campo das necessidades a serem protegidas para a garantia do padrão adequado de vida. (Silva e Diniz, 2012, p. 265)

A Convenção Internacional entende a pessoa deficiente como sendo "aquela que possui impedimentos de longo prazo de natureza física, mental, intelectual ou sensorial, os quais, em interação com diversas barreiras, podem obstruir sua

4. A Convenção Internacional sobre os Direitos das Pessoas com Deficiência, assinada em Nova York, em 30/3/2007, integrou-se à Constituição da República, aprovada pelo Congresso Nacional, pelo Decreto Legislativo n. 186, de 9/7/2008, e sancionada pelo Presidente da República, por intermédio do Decreto n. 6.949, de $25 / 8 / 2009$. Isso foi possível com base nos termos do artigo $5^{\circ}, \S 3^{\circ}$, da $\mathrm{CF} / 88$, que determinam que os tratados e as convenções internacionais sobre direitos humanos, que forem ratificados pelo Brasil, observando os critérios formais de aprovação das emendas constitucionais, serão equivalentes a estas. 
participação plena e efetiva na sociedade em igualdades de condições com as demais pessoas" (Brasil, 2009). Portanto, a referência ao termo longo prazo não define o tempo para se constituírem os impedimentos. Parafraseando Silva e Diniz (2012), a ideia era garantir a proteção aos deficientes, em oposição a situações muito transitórias e específicas que não demandassem a construção de uma política ampla e de uma legislação própria. Os princípios protetivos da deficiência, instituídos pela Convenção e, em especial, o da proteção à igualdade, são suficientes para entender o sentido de quais impedimentos importam para a assistência. Quando a Convenção fixa que o deficiente é aquele que possui impedimentos de longo prazo, o objetivo é o de delimitar as fronteiras entre os diferentes estados corporais e, assim, contribuir para o reconhecimento.

No entanto, tal perspectiva não foi adotada pelo INSS quando da modificação feita na forma de avaliação médico-pericial e social. Por meio de um Ato Institucional, editado em 24 de maio de 2011, através da Portaria conjunta MDS/ INSS n. 01 e regulamentado internamente pelo Memorando Circular Conjunto Dirsat/Dirben/Dirat/INSS n. 03, a normativa definiu, então, que, para fins de concessão do BPC, se consideraria pessoa com deficiência aquela com impedimentos que, associados às diversas barreiras, incapacitam o indivíduo para a vida independente e para o trabalho pelo prazo mínimo de dois anos.

No intuito de avaliar esta condição de impedimento de longo prazo foram introduzidos novos indicadores no instrumental de avaliação da pessoa com deficiência para acesso ao BPC. Entre eles, a indicação, pelo perito médico, de uma das três alternativas: (1) sim; (2) não é possível prever nesse momento, mas há chances de impedimentos se estenderem por longo prazo; e (3) não. O contexto social do requerente terá impacto, com reconhecimento ou não do direito ao benefício, caso a escolha do perito seja pelos indicadores 1 ou 2, mantendo-se a concessão ou indeferimento dependentes da combinação dos qualificadores dos três componentes da avaliação (fatores ambientais, atividades e participação, e funções do corpo). No entanto, caso opte pela alternativa 3, o benefício será indeferido, independentemente do grau de incapacidade existente no momento da avaliação, desconsiderando-se, inclusive, a avaliação social e médico-pericial realizadas.

Diante dos inúmeros questionamentos de profissionais que realizavam a avaliação social, a respeito da hipótese de haver prevalência da avaliação médica sobre a decisão para o deferimento ou indeferimento dos requerimentos, a 
Coordenadoria Geral de Revisão e Controle dos Benefícios do MDS emitiu uma Nota Técnica (Brasil, 2011) com o intuido de visualizar os efeitos iniciais do aprimoramento do instrumental de avaliação, após a implantação da Portaria Conjunta MDS/INSS n. 01. Dos resultados alcançados, constatou-se que 8,51\% dos requerimentos com impedimentos temporários foram indeferidos, quando os resultados das combinações dos qualificadores dos domínios do atual instrumento de avaliação da pessoa com deficiência indicavam que estes deveriam ter sido deferidos.

De acordo com a regulamentação do atual instrumental de avaliação, entretanto, seria o conteúdo das informações constantes tanto na avaliação médica quanto na avaliação social, ou seja, uma análise conjunta, o que deveria definir a decisão pelo deferimento ou indeferimento do benefício. E isto não foi, também, o que indicaram os resultados obtidos no presente estudo em relação aos 204 requerimentos analisados, correspondentes ao período posterior à implantação da Portaria Conjunta MDS/INSS n. 01, de 24 de maio de 2011, quais sejam: $49,02 \%$ dos benefícios requeridos indeferidos por se constatar deficiência temporária, que, somados ao número de indeferimentos por não haver incapacidade para a vida independente e para o trabalho $(6,86 \%)$, resultam em um total de indeferimentos por não constatação de incapacidade, no montante de 55,88\% (Tabela 3).

Estes resultados confirmam o que já foi indicado por Silva e Diniz (2012, p. 266) quando afirmam que

são os peritos médicos do INSS quem estabelecem quais impedimentos são estados de necessidade para a proteção social. A definição de um corpo com impedimentos como o de uma pessoa com deficiência não é um exercício neutro de classificação dos corpos, mas um julgamento moral que combina ideais de normalidade e produtividade. A perícia é um exercício de soberania médica no campo dos direitos sociais.

Na avaliação, a decisão final de concessão do BPC para PcD compete ao perito médico, que tem a responsabilidade legal de deferir ou indeferir o benefício, baseado em uma espécie de "prazo" de validade de uma incapacidade, o que, por sua vez, aponta para a existência do predomínio da avaliação médica do perito. Nega-se, assim, o fato de que uma pessoa mesmo com leve ou mode- 
Tabela 3. Distribuição dos requerimentos de BPC para PcD, deferidos e indeferidos, segundo o critério de impedimento de longo prazo - Assis Chateaubriand, PR

\begin{tabular}{|l|c|c|c|c|c|c|c|c|}
\hline \multirow{2}{*}{ Situação/Motivo } & \multicolumn{9}{c|}{ Impedimento de longo prazo } \\
\cline { 2 - 10 } & \multicolumn{2}{|c|}{ Sim } & \multicolumn{2}{c|}{ Não } & \multicolumn{2}{c|}{ NPP } & \multicolumn{2}{c|}{ Total } \\
\cline { 2 - 10 } & N & $\%$ & N & $\%$ & N & $\%$ & N & $\%$ \\
\hline Benefícios deferidos & 47 & - & - & - & 25 & 12,26 & & 35,30 \\
\hline $\begin{array}{l}\text { Indeferido por deficiência } \\
\text { temporária }\end{array}$ & - & 23,04 & 100 & 49,02 & - & - & 100 & 49,02 \\
\hline $\begin{array}{l}\text { Indeferido por não haver } \\
\text { incapacidade p/ vida } \\
\text { independente e p/ trabalho }\end{array}$ & 2 & 0,98 & - & - & 12 & 5,88 & 14 & 6,86 \\
\hline $\begin{array}{l}\text { Indeferido por renda per } \\
\text { capita familiar }>=1 / 4 \\
\text { salário mínimo DER }\end{array}$ & 10 & 4,90 & - & - & 8 & 3,92 & 18 & 8,82 \\
\hline Total & 60 & 29,41 & 96 & 47,06 & 48 & 23,52 & 204 & 100,00 \\
\hline
\end{tabular}

Fonte: SIAVBPC INSS. Elaboração própria.

NPP: Não é possível prever nesse momento, mas há chances de impedimentos se estenderem por longo prazo. $\mathrm{N}$ : número. \%: percentagem. $>=1 / 4$ : renda per capita maior ou igual a um quarto de salário mínimo na data de entrada do requerimento.

rada habilidades, possa enfrentar graves restrições em consequência de variáveis difíceis de serem mensuradas, tais como discriminação, preconceito ou barreiras sociais de outra ordem, além da condição de pobreza em que se encontre.

A Lei n. 12.435/2011, ao definir a incapacidade de longo prazo como sendo aquela que causa impedimento por no mínimo dois anos, limita ainda mais o acesso e o reconhecimento de um direito e exclui, automaticamente, várias condições que poderiam ser entendidas como deficiências para o BPC, de maneira que, em detrimento das variáveis sociológicas, volta-se à sobrevalorização do discurso médico da deficiência.

Não se confirma, portanto, como expresso na CIF, que a previsão de um conjunto de informações sobre o diagnóstico e a funcionalidade forneceria uma 
imagem mais ampla e mais significativa da saúde das pessoas. Ao contrário, comprovam-se as limitações existentes no instrumento de avaliação para discutir as formas de atuação das políticas públicas que garantam a proteção social dos requerentes, cuja deficiência não foi considerada de longo prazo. Cabe, então, questionar o papel do Estado no atendimento às necessidades básicas daqueles que não se enquadraram no perfil para a concessão do BPC. O que fazer com as pessoas cuja incapacidade pode perdurar um mês, dois meses ou 729 dias? É possível estipular um prazo razoável para recuperação de uma incapacidade? Há possibilidade de se prever uma data em que haverá recuperação? Como ficam a individualidade, o contexto familiar, os fatores sociais, econômicos ou de ordem emocional e afetivos?

A dignidade da pessoa humana não pode ser mensurada com critérios matemáticos e objetivos, e ao agregar-se, ao termo da lei, a expressão [impedimento de longo prazo], transita-se, claramente, para o cenário de extrema restrição do benefício, na medida em que esta traz um critério objetivo e de ordem temporal para a análise desta incapacidade. Desta forma, não basta, agora, ser incapaz para a vida independente e para o trabalho, mas, segundo a lei, deve esta incapacidade perdurar por dois anos ou mais, o que deixa perceptível o caráter excludente das pessoas com deficiência, contrariando a finalidade do benefício e afastando ainda mais o cidadão do direito social.

\section{Considerações finais}

O estudo desenvolvido indica que a utilização de parâmetros baseados na CIF, para a avaliação da $\mathrm{PcD}$, manteve a estrutura de exclusão intacta pela não observância efetiva da questão contextual dos requerentes e pelo corpo com impedimento continuar a ser classificado por narrativa biomédica. A CIF e, por conseguinte, os documentos a ela referenciados, são um reflexo da visão hegemônica, segundo a qual, o entendimento comum ainda recai sobre os determinantes do processo saúde-doença, não apresentando as iniquidades em saúde como produto das desigualdades sociais e não reafirmando o papel do Estado para superá-las.

A incorporação dos fatores contextuais (aspectos ambientais e sociais), na forma de avaliação atual, não tem sido relevante na alteração definitiva dos 
limites excludentes sob os quais está regulamentado o BPC, pois este não remete o requerente à contextualização das mudanças recentes no mundo do trabalho, a financeirização do capital e a mercantilização das políticas públicas, que ocasionam desemprego, precarização do trabalho, redução da proteção social e desesperança por uma vida digna.

Nesse sentido, concorda-se com Silva (2013), quando esta aponta que o atual modelo da política de Assistência Social brasileira consiste em arranjos que a própria ordem do capital constitui para mascarar a real dimensão da expressão [ofensiva do capital aos mais elementares direitos do trabalho], o que dá suporte à superexploração do trabalho e equaliza a pobreza entre os próprios trabalhadores, para resguardar a riqueza produzida no país do conflito sobre a sua repartição, e para transferi-la para a expansão do capital em escala internacional.

Isto nos leva a crer que a introdução da avaliação social baseada na CIF, como preconiza o Decreto n. 6.214/2007, é expressão da necessidade da política social de reorganizar-se para cumprir seu papel político/ideológico de reprodutora da concepção de mundo neoliberal e da reprodução das relações de produção capitalista, que reafirmam o país na lógica do capital globalizado e do projeto neoliberal, e não como forma de ampliação de acesso aos direitos constitucionais.

Seria necessário que gestores, técnicos e trabalhadores se comprometessem para adequar, não só o marco legal, mas, também, o regime pericial médico e social de avaliação da deficiência, no sentido de se efetivarem os princípios da Convenção sobre os direitos das pessoas com deficiência, a partir da necessidade de se avaliar a restrição de participação do corpo com impedimentos na vida social.

Uma das possibilidades poderia ser a avaliação social, realizada por assistentes sociais, ter o mesmo espaço de legitimidade que o da perícia biomédica.

Para a consolidação da política social não contributiva, no âmbito da previdência social brasileira, e para aproximar os requerentes do BPC da cidadania de direito, o deferimento ou o indeferimento do benefício deveria resultar de uma análise conjunta, da qual prevalecesse a decisão final sobre o BPC para PcD.

Recebido em 31/10/2013 - Aprovado em 17/3/2014 


\section{Referências bibliográficas}

ALMEIDA, E. H. R. Aspectos bioéticos da perícia médica previdenciária. Revista Bioética (Impr.), Brasília, v. 19, n. 1, p. 277-98, 2011.

BARROS. J. A. C. Pensando o processo saúde doença: a que responde o modelo biomédico? Saúde e Sociedade, São Paulo, v. 11, n. 1, jan./jul. 2002.

BRASIL. Decreto n. 6.214, de 26 de setembro de 2007. Regulamenta o Benefício de Prestação Continuada da Assistência Social devido à pessoa com deficiência e ao idoso de que trata a Lei n. 8.742, de 7 de dezembro de 1993, e a Lei n. 10.741, de $1^{\circ}$ de outubro de 2003, acresce parágrafo ao art. 162 do Decreto n. 3.048, de 6 de maio de 1999, e dá outras providências. Diário Oficial da União, Brasília, 28 set. 2007a, p. 16.

. Decreto n. 6.949, de 25 de agosto de 2009. Promulga a Convenção Internacional sobre os Direitos das Pessoas com Deficiência e seu Protocolo Facultativo, assinados em Nova York, em 30 de março de 2007. Diário Oficial da União, Brasília, 25 ago. 2009, p. 3.

- Ministério do Desenvolvimento Social e Combate à Fome. Avaliação das pessoas com deficiência para acesso ao Beneficio de Prestação Continuada da assistência social: um novo instrumento baseado na Classificação Internacional de Funcionalidade, Incapacidade e Saúde. Brasília: MDS; MPS, 2007b. 192 p. ISBN 978-8560700-04-2.

; _. Secretaria Nacional de Assistência Social. Departamento de Benefícios Assistenciais. Nota Técnica DBA/SNAS/MDS, Brasília, n. 69, 26 out. 2010.

; _. Secretaria Nacional de Assistência Social. Departamento de Benefícios Assistenciais. Coordenação Geral de Controle e Informações de Benefícios. Nota técnica $D B A / S N A S / M D S$, Brasília, n. 65, [2011e].

Ministério da Previdência Social. Secretaria de Políticas de Previdência Social. Coordenação-Geral de Estatística, Demografia e Atuária. Boletim Estatístico da Previdência Social, Brasília, MPS, v. 17, n. 2, fev. 2012.

. Ministério da Saúde. Secretaria Executiva. Subsecretaria de Assuntos Administrativos. Manual de perícia médica. 2. ed. rev. Brasília: MS, 2005. 128 p. il., tab. ISBN 85-334-0880-3. (Série A. Normas e Manuais Técnicos.)

; __ Secretaria Executiva. Subsecretaria de Assuntos Administrativos. Manual de perícia médica. 2. ed. rev. Brasília: Ministério da Saúde, 2005. 128 p. il., tab. ISBN 85-334-0880-3. (Série A. Normas e Manuais Técnicos). 
DINIZ, D.; SQUINCA, F.; MEDEIROS, M. Qual deficiência?: perícia médica e assistência social no Brasil. Cad. Saúde Pública, Rio de Janeiro, v. 23, n. 1, p. 2589-96, nov. 2007. Disponível em: $<$ http://www.scielo.br/scielo.php?script=sci_arttext\&pid=S0102-311X2007001100006\&lng=en\&nrm=iso>. Acesso em: 19 dez. 2011.

GOMES, M. M. Epilepsia e Incapacidade Laborativa. Journal of Epilepsy and Clinical Neurophysiology, Porto Alegre, v. 15, n. 3, p. 130-134, set. 2009.

IVO, A. B. L.; SILVA, A. B. A. O hiato do direito dentro do direito: os excluídos do BPC. Katálysis, Florianópolis, v. 14, n. 1, p. 32-40, jun. 2011.

JÚNIOR, A. J. C. Questões/problemas em perícias médicas nos casos de depressão. Revista Hospital Universitário Pedro Ernesto, Rio de Janeiro, v. 10, n. 2, p. 66-77, abr./ jun. 2011.

LACAZ, F. A. C. O campo Saúde do Trabalhador: resgatando conhecimentos e práticas sobre as relações trabalho-saúde. Cadernos de Saúde Pública, Rio de Janeiro, v. 23, n. 4, p. 757-766, abr. 2007.

LAURELL, A. C.; NORIEGA, M. Para o estudo da Saúde na sua relação com o processo de trabalho. In: . Processo de produção e saúde: trabalho e desgaste operário. São Paulo: Hucitec, 1989. 333p.

MEDEIROS, M.; GRANJA, F. H.; SAWAYA NETO, M. Mudança do Conceito de Família do Benefício de Prestação Continuada. Rio de Janeiro: IPEA, jul. 2009. (Textos para Discussão, n. 1411.)

MELO, M. B.; BRANT, L. C. Ato médico: perda da autoridade, poder e resistência. Psicologia: Ciência e Profissão, Brasília, v. 25, n. 1, p. 14-29, mar. 2005.

MENDES, J.; WUNSCH, D. S. Serviço Social e a saúde do trabalhador: uma dispersa demanda. Serviço Social \& Sociedade, São Paulo, n. 107, p. 461-481, jul./set. 2011.

MENDES, K. D. S.; SILVEIRA, R. C. C. P.; GALVÃO, C. M. Revisão integrativa: método de pesquisa para a incorporação de evidências na saúde e na enfermagem. Texto \& Contexto - Enfermagem, Florianópolis, v. 17, n. 4, p. 758-64, out./dez. 2008.

MENDES, R.; DIAS, E. C. Da medicina do trabalho à saúde do trabalhador. Revista de Saúde Pública, revista da USP, São Paulo, v. 25, n. 5, p. 3-11, out. 1991.

MUROFUSE, Neide Tiemi. O adoecimento dos trabalhadores de enfermagem da Fundação Hospitalar do Estado de Minas Gerais: reflexo das mudanças do mundo do trabalho. Ribeirão Preto. Tese (Doutorado) Escola de Enfermagem de Ribeirão Preto. Universidade de São Paulo, 2004. 
OLIVEIRA, R. M. R. A abordagem das lesões por esforços repetitivos/distúrbios osteomusculares relacionados ao trabalho - LER/DORT no Centro de Referência em Saúde do Trabalhador do Espirito Santo — CRST/ES. Dissertação (Mestrado) - Banco de Teses da ENSP/Fiocruz. Fundação Oswaldo Cruz, Escola Nacional de Saúde Pública, 2001. 143 p.

PENALVA, J.; DINIZ, D.; MEDEIROS, M. O Benefício de Prestação Continuada no Supremo Tribunal Federal. Sociedade e Estado, Brasília, v. 25, n. 1, jan./abr. 2010.

PINTO JUNIOR, A. G.; BRAGA, A. M. C. B.; ROSELli-CRUZ, A. Evolução da saúde do trabalhador na perícia médica previdenciária no Brasil. Ciência \& Saúde Coletiva, Rio de Janeiro, v. 17, n. 10, p. 2841-2849, out. 2012.

SANTOS, W. R. Assistência social e deficiência no Brasil: o reflexo do debate internacional dos direitos das pessoas com deficiência. Serviço Social em Revista, Londrina, v. 13, n.1, p. 80-101, jul./dez. 2010.

. Deficiência e BPC: o que muda na vida das pessoas atendidas? Ciência \& Saúde Coletiva, Rio de Janeiro, v. 16, supl. 1, p. 787-796, 2011.

SILVA, J. L. P.; DINIZ, D. Mínimo social e igualdade: deficiência, perícia e benefício assistencial na LOAS Katálysis, Florianópolis, v. 15, n. 2, p. 262-269, jul./dez. 2012.

SILVA, S. S. S. Contradições da Assistência Social no governo "neodesenvolvimentista" e suas funcionalidades ao capital. Serviço Social \& Sociedade, São Paulo, n. 113, mar. 2013.

SPOSATI, A. Benefício de Prestação Continuada como mínimo social. In: (Org.). Proteção Social de cidadania: inclusão de idosos e pessoas com deficiência no Brasil, França e Portugal. São Paulo: Cortez, 2004.

. Modelo brasileiro de proteção social não contributiva: concepções fundantes. In: BRASIL. Ministério do Desenvolvimento Social e Combate à Fome. Concepção e gestão da proteção social não contributiva no Brasil. Brasília: MDS; Unesco, 2009. p. 13-56. 